\title{
4-Hydroxynonenal (HNE), a Toxic Aldehyde in Fried Chicken from Fast Food Restaurants and a Grocery Store
}

\author{
Ning Yin, Don W. Shoeman, Katherine A. Klammer, A. Saari Csallany* \\ Department of Food Science and Nutrition, University of Minnesota, Saint Paul, MN, USA \\ Email: *ascsalla@umn.edu
}

How to cite this paper: Yin, N., Shoeman, D.W., Klammer, K.A. and Csallany, A.S. (2020) 4-Hydroxynonenal (HNE), a Toxic Aldehyde in Fried Chicken from Fast Food Restaurants and a Grocery Store. Food and Nutrition Sciences, 10, 82-97.

https://doi.org/10.4236/fns.2020.112008

Received: December 4, 2019

Accepted: February 7, 2020

Published: February 10, 2020

Copyright $\odot 2020$ by author(s) and Scientific Research Publishing Inc. This work is licensed under the Creative Commons Attribution International License (CC BY 4.0).

http://creativecommons.org/licenses/by/4.0/

\begin{abstract}
The lipid oxidation product, the toxic 4-hydroxynonenal, was measured for fried chicken in commercial samples from two fast food restaurants and one commercial establishment. The fried chicken samples were breasts, thighs, chicken nuggets and popcorn chicken. Fried chicken samples were separated to breast skin and meat, and thigh skin and meat. Chicken nuggets and popcorn chicken were not separated from the coating materials and the meat was analyzed together. Samples were analyzed for total fat, fatty acid distribution, reactivity with thiobarbituric acid (TBAR), measuring the secondary lipid peroxidation products such as aldehydes, ketones and related carbonyl compounds. Samples were analyzed for HNE, a toxic aldehyde using high performance liquid chromatography (HPLC). Fatty acid distribution showed in breast and thigh meats, a higher level of palmitic acid, compared to the breast and thigh skins. TBAR values were significantly higher in all breast meats compared to skins. TBAR values were significantly higher in thigh meat than in skin samples. HNE concentrations ( $\mu \mathrm{g} \mathrm{HNE/g} \mathrm{fat)} \mathrm{were} \mathrm{significantly} \mathrm{very}$ low in breast skins compared to breast meat. HNE concentration was generally higher in thigh meat than skin but not in every sample. In chicken nuggets, both the TBAR value and HNE concentration were much higher from one establishment than from the two others. Chicken nuggets TBAR and HNE concentrations resembled one of the chicken nugget samples. The average toxic HNE concentration for $100 \mathrm{~g}$ fried chicken breast (skins + meat) was $12.55 \mu \mathrm{g}$ and for thighs (skin + meat) was $26.76 \mu \mathrm{g}$. The average total HNE concentration was 2.1 times higher in the fried chicken thighs than in the breasts. It is clear that HNE is produced during the heating process of oils and incorporated into the fried meat and skin samples during the frying process. If HNE, a toxic aldehyde, is consumed with the food, over long periods of time it could be related to a number of pathological conditions.
\end{abstract}




\section{Keywords}

Fast Food, Fried Chicken, Lipid Oxidation, 4-Hydroxynoninal (HNE), TBARS, Toxic Aldehyde, Fats

\section{Introduction}

Lipid peroxidation is an autocatalytic process in the presence of free radicals and molecular oxygen causing the deterioration of fatty acids (FA) in oils and fats [1]-[6]. This process is the major course of deterioration for many foods containing fats and oils leading to quality and nutritional losses [7] [8] [9]. The oxidative degradation of FA leads to a variety of secondary lipid peroxidation products. These products include various lipophilic aldehydes such as alkanals, alkenals, alkadienals and hydroxyalkenals and these compounds are readily absorbed from the diet [10] [11] [12] [13]. One class of aldehydes, the toxic 4-hydroxyalkenals, generated from lipid peroxidation of unsaturated FA are of special importance because of their reactivity to biomolecules [14] [15]. The cytotoxicity of 4-hydroxynonenal (HNE) [16] has been found to be formed from the oxidation of n-6 FA, including linoleic acid [12] [15] [17] which is high in polyunsaturated fatty acids (PUFA). This polar aldehyde contains unsaturation between the $\alpha$ and $\beta$ carbons and a hydroxyl group on the carbon 4 position. Their chemical structures make these aldehydes very reactive to amino, sulfhydryl and thiol groups and therefore react aggressively with biological compounds. Among the four $\alpha, \beta$, 4-hydroxyaldehydes, the 9 carbon containing HNE, was found to be the most reactive and toxic compound [18]-[26]. Its toxicity has been demonstrated in the literature by its reaction to DNA and RNA in low concentrations and related to a number of pathological conditions including inflammatory and degenerative processes such as atherosclerosis, liver damage, Parkinson's, Alzheimer's and other diseases [27]-[33]. It has been shown that the precursor for HNE is linoleic acid [34] and a number of high PUFA containing oils used for commercial fryings are high in this fatty acid.

A number of previous experiments by the author have shown the formation of HNE due to heat treatments in various oils [34]-[39]. HNE has also been shown to incorporate into fried food [40] [41]. Since HNE has been shown to be absorbed from the diet and metabolized [42], it is important to investigate its formation in commercially fried chicken. Since fried chickens are consumed in large quantities from commercial establishments, the objective of the present study was to measure the concentration of the toxic aldehyde HNE, in commercially fried chicken breasts, thighs, chicken nuggets and popcorn chicken obtained from local fast food restaurants and a local common grocery store.

\section{Experimental Procedures}

\subsection{Chemicals and Materials}

All solvents used were HPLC grade. 2,4-dinitrophenylhydrazine (DNPH) was 
obtained from Eastman Kodak Co. (Rochester, NY); 2-thiobarbituric acid, thichloreacetic acid, HPLC-grade methanol, HPLC-grade water, HPLC-grade dichloromethane, ASC grade methanol and boron trifluoride-methanol solution from Sigma-Aldrich Co. (St. Louis, MO); Sodium thiosulfate from Fisher Scientific (Fairlawn, NJ), hydrochloric acid from Mallinckrodt Baker Inc. (Paris, KY). HPLC-grade hexane was from EMD chemicals, Inc. (Gibbstown, NJ), HNE standard from Cayman Chemicals Co. (Ann Arbor, MI); thin-layer chromatography plates (TLC) from EMD Millipore Corp. (Billeria, MA).

\subsection{Instruments}

Fatty acid distribution was measured on a gas chromatograph (GC) (5830A; Hewlett-Packard, Saginaw, MI, USA) equipped with a Carbowax capillary column, $15 \mathrm{~m}$, id of $0.53 \mathrm{~mm}$ All Tech Econo Cap \#119563 (Deerfield, IL, USA). Reference standards are for GC from Nu-Chek Prep, Inc. (Elysian, MN).

The high performance liquid chromatograph (HPLC) system consisted of a sample injector 712 WISP (Waters Milford, MA, USA), a solvent delivery system 9050 Varian (Walnut Creek, CA, USA) and a UV detector (Spectra series UV 150). The HPLC column was Ultrasphere ODS $(5 \times 4.6 \mathrm{~mm}, 25 \mathrm{~cm})$ (Hichrom, Berkshire, UK).

\subsection{Sample Collection}

Fried chicken breast and thighs, chicken nuggets and popcorn chicken samples were purchased between $2-3 \mathrm{pm}$ from two different local fast food restaurants and one local store (St. Paul, MN; suburb of Roseville, 55113). The chicken breast and thigh samples were immediately separated from the skin, meat and bones. The bones were discarded. The chicken nuggets and popcorn chicken samples were not separated between meat and the cover substance. All samples were placed immediately into separated plastic bags and stored at $-70^{\circ} \mathrm{C}$ until analysis.

\subsection{Fat Extractions of Fried Chicken Samples}

About $50 \mathrm{~g}$ of the separated skin or meat samples, from chicken breasts and thighs, and $50 \mathrm{~g}$ of the complete samples of chicken nuggets and popcorn chicken were minced with $100 \mathrm{~mL}$ hexane in a blender for $1-2 \mathrm{~min}$., filtered and the filtrate collected. The hexane extraction was repeated two more times with $100 \mathrm{~mL}$ hexane. The combined hexane extracts were shaken with $50 \mathrm{~g}$ of anhydrous sodium sulfate for $2 \mathrm{~min}$., filtered and the filtrate was shaken one more time with $50 \mathrm{~g}$ of anhydrous sodium sulfate for drying. After filtration, the hexane was evaporated using a vacuum system. All the extracted fats were stored at $-20^{\circ} \mathrm{C}$ under $\mathrm{N}_{2}$ gas until analysis. The fat extractions were conducted in duplicates for all samples and the extracted fat for each type of sample combined.

\subsection{Thiobarbituric Acid-Reactive Substances Determination}

Thiobarbituric acid-reactive substances (TBARS) were measured in triplicate by 
the method of Buege and August [42] using malondialdehyde as a standard.

\subsection{HPLC Determination}

The formation of HNE was detected using the method of Seppanen and Csallany [36]. Duplicate oil samples were analyzed after purification using high performance liquid chromatography (HPLC). The total aldehyde contents were calculated as described by Schulte [43].

Briefly, $1 \mathrm{~g}$ of duplicate extracted fat samples were mixed each with $5 \mathrm{ml}$ of DNPH reagent and kept overnight at room temperature to form hydrazine derivatives with aldehydes, ketones and related carbonyl compounds, which were extracted with methanol/water $(75: 25 \mathrm{vol} / \mathrm{vol})$ to separate the oil and the extract re-extracted with dichloromethane. The DNPH derivatives were separated by TLC on silica gel to polar and nonpolar derivatives and osazones with dichloromethane. The polar hydrazones, which include HNE, were eluted with methanol from the TLC plate and the methanol extract was evaporated by $\mathrm{N}_{2}$ gas to $1 \mathrm{~mL}$. Aliquots of the sample injected in duplicates to the HPLC system for quantification of HNE, using a flow rate of $0.8 \mathrm{~mL} / \mathrm{min}$ with methanol water $(50 / 50$ $\mathrm{vol} / \mathrm{vol}$ ) followed by linear gradient to $100 \%$ methanol for a total elution time of $40 \mathrm{~min}$. Absorbance was monitored at $378 \mathrm{~nm}$. HNE was quantified using pure HNE-DNPH standards. Identification was determined by comparison to retention time and co-chromatography with the pure HNE-DNPH standards. Pure HNE-DNPH standard was used daily to measure the reproducibility. Sensitivity of measurement is $1 \mathrm{ng}$ per injection. Figure 1 is a typical chromatogram of HNE samples (Figure 1(a), Figure 1(b)) and the corresponding standards (Figure $1(\mathrm{c})$, Figure $1(\mathrm{~d})$ ).

\subsection{Fatty Acid Distribution}

The fatty acid distribution of extracted samples was determined using gas chromatography (GC) as described by Metcalf [44]. Approximately $100 \mathrm{mg}$ of extracted fats were methylated using borontrifluoride-methanol $\left(\mathrm{BF}_{3}\right)$. The fatty acid methyl esters (FAME) dissolved in hexane and injected to the GC. The injector, oven and detector temperatures were $230^{\circ} \mathrm{C}, 220^{\circ} \mathrm{C}$ and $250^{\circ} \mathrm{C}$, respectively. The fatty acid distribution was measured by comparing to the fatty acid standards. Results are expressed as \% of the total fatty acids.

\subsection{Statistical Analysis}

Analysis of variance was used to determine significant differences between samples. The Tukey test was conducted to calculate $P$ values. Significant differences were determined at $\mathrm{P} \leq 0.05$.

\section{Results and Discussion}

\section{1) Weight of Samples and Percent of Extracted Fat}

Tables 1-3 show the weights of samples and the percent of extracted fat in the 


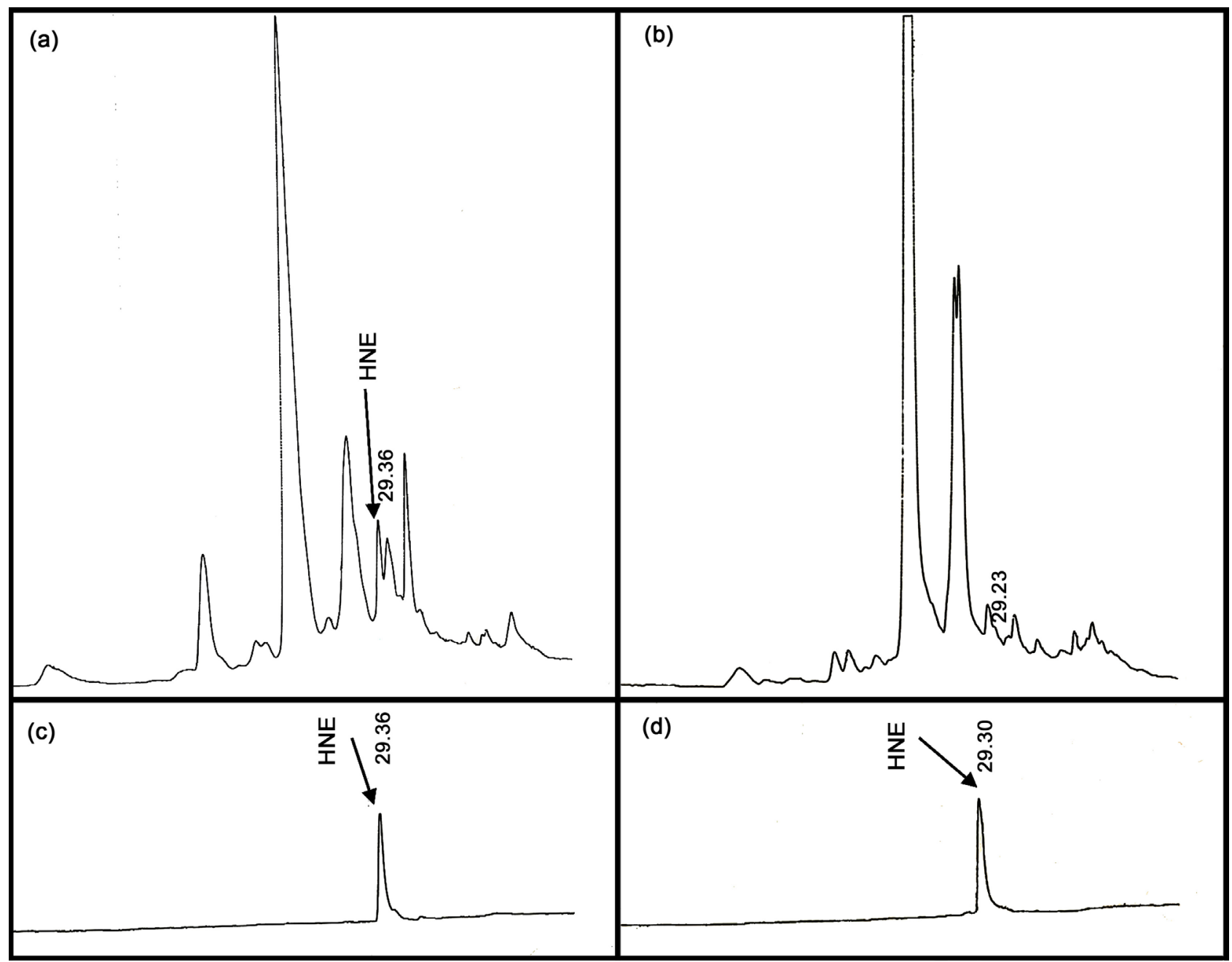

Figure 1. Typical HPLC chromatogram of HNE in fat extracted from (a) Chicken breast meat. (b) Chicken breast skin. (c), (d) Corresponding HNE standard.

fried chicken breasts, thighs, chicken nuggets and popcorn chicken samples obtained from two different fast food restaurants and a grocery store. As it was expected, the fat extracted from the skin of fried chicken (including its coating) was much higher than the extracted fat in the breast and thigh meats. The percent of extracted fat was only $5.24 \%$ to $6.96 \%$ in the breast meat and $10.04 \%$ to $12.13 \%$ in the thigh meat. The percent extracted fat in both breast and thigh skins was similarly high, $32.73 \%$ to $40.65 \%$ in breast skin and $35.40 \%$ to $40.71 \%$ in thigh skin. The average ratio of extracted fat was 5.8 times higher in the skin than in the meat of breast and 3.37 times higher in the skin of thigh than in the meat. The percent of extracted fat was quite similar in chicken nugget samples, $19.47 \%$ to $21.30 \%$, and only a little higher, $23.88 \%$ in popcorn chicken, which are smaller in size than chicken nuggets and contain generally less meat and more coating material. In general, the fat concentration in chicken nuggets and popcorn chicken is about 2 to 3 times higher than in the thigh or breast meats.

\section{2) Fatty Acid Distribution}


Table 1. Weight of samples and percent of extracted fat in chicken breasts meat and skin from 3 different brands.

\begin{tabular}{|c|c|c|c|c|c|c|}
\hline Sample & $\begin{array}{c}\text { Weight } \\
\text { of whole } \\
\text { breast (g) }\end{array}$ & $\begin{array}{l}\text { Weight } \\
\text { of breast } \\
\text { meat (g) }\end{array}$ & $\begin{array}{c}\text { Percent } \\
\text { of meat } \\
\text { in whole } \\
\text { breast } \\
(\%)\end{array}$ & $\begin{array}{l}\text { Extracted } \\
\text { fat from } \\
\text { meat (g) }\end{array}$ & $\begin{array}{c}\text { Percent of } \\
\text { fat } \\
\text { extracted } \\
\text { from meat } \\
(\%)\end{array}$ & $\begin{array}{c}\text { Average } \% \\
\text { of extracted } \\
\text { fat }\end{array}$ \\
\hline Breast 1 & 214.56 & 136.99 & 63.85 & 9.54 & 6.96 & \\
\hline Breast 2 & 227.32 & 116.52 & 51.26 & 6.11 & 5.24 & 6.13 \\
\hline \multirow[t]{2}{*}{ Breast 3} & 249.80 & 126.67 & 50.42 & 7.87 & 6.20 & \\
\hline & & $\begin{array}{l}\text { Weight } \\
\text { of breast } \\
\text { skin (g) }\end{array}$ & $\begin{array}{c}\text { Percent } \\
\text { of skin in } \\
\text { whole } \\
\text { breast } \\
(\%)\end{array}$ & $\begin{array}{l}\text { Extracted } \\
\text { fat from } \\
\text { skin (g) }\end{array}$ & $\begin{array}{c}\text { Percent of } \\
\text { fat } \\
\text { extracted } \\
\text { from skin } \\
(\%)\end{array}$ & $\begin{array}{c}\text { Average } \% \\
\text { of extracted } \\
\text { fat }\end{array}$ \\
\hline Breast 1 & & 46.56 & 21.70 & 18.93 & 40.65 & \\
\hline Breast 2 & & 85.78 & 37.74 & 28.08 & 32.73 & 35.69 \\
\hline Breast 3 & & 95.81 & 38.28 & 32.20 & 33.69 & \\
\hline
\end{tabular}

Table 2. Weight of samples and percent of extracted fat in chicken thighs meat and skin from 3 different brands.

\begin{tabular}{|c|c|c|c|c|c|c|}
\hline Sample & $\begin{array}{l}\text { Weight } \\
\text { of whole } \\
\text { thigh (g) }\end{array}$ & $\begin{array}{l}\text { Weight } \\
\text { of thigh } \\
\text { meat (g) }\end{array}$ & $\begin{array}{c}\text { Percent } \\
\text { of meat } \\
\text { in thigh } \\
(\%)\end{array}$ & $\begin{array}{l}\text { Extracted } \\
\text { fat from } \\
\text { meat }(\mathrm{g})\end{array}$ & $\begin{array}{l}\text { Percent of } \\
\text { fat } \\
\text { extracted } \\
\text { from meat } \\
\quad(\%)\end{array}$ & $\begin{array}{c}\text { Average \% } \\
\text { extracted } \\
\text { fat }\end{array}$ \\
\hline Thigh 1 & 159.65 & 82.91 & 51.93 & 10.06 & 12.13 & \\
\hline Thigh 2 & 151.32 & 61.66 & 40.75 & 6.78 & 10.99 & 11.05 \\
\hline \multirow[t]{2}{*}{ Thigh 3} & 153.87 & 60.35 & 39.23 & 6.07 & 10.04 & \\
\hline & & $\begin{array}{l}\text { Weight } \\
\text { of thigh } \\
\text { skin (g) }\end{array}$ & $\begin{array}{c}\text { Percent } \\
\text { of skin in } \\
\text { whole } \\
\text { thigh (\%) }\end{array}$ & $\begin{array}{c}\text { Extracted } \\
\text { fat from } \\
\text { skin (g) }\end{array}$ & $\begin{array}{l}\text { Percent of } \\
\text { fat } \\
\text { extracted } \\
\text { from skin } \\
\quad(\%)\end{array}$ & $\begin{array}{c}\text { Average \% } \\
\text { extracted } \\
\text { fat }\end{array}$ \\
\hline Thigh 1 & & 45.28 & 28.36 & 16.03 & 35.40 & \\
\hline Thigh 2 & & 67.56 & 44.65 & 24.11 & 35.69 & 37.26 \\
\hline Thigh 3 & & 72.84 & 47.29 & 29.61 & 40.71 & \\
\hline
\end{tabular}

Table 3. Weight of samples and percent of extracted fat in chicken nuggets and popcorn chicken.

\begin{tabular}{ccccc}
\hline Sample & $\begin{array}{c}\text { Pieces } \\
\text { (in one } \\
\text { sample) }\end{array}$ & $\begin{array}{c}\text { Total weight of } \\
\text { samples (g) }\end{array}$ & $\begin{array}{c}\text { Weight of } \\
\text { extracted fat from } \\
\text { total sample (g) }\end{array}$ & $\begin{array}{c}\text { Percent of } \\
\text { fat (\%) }\end{array}$ \\
\hline Chicken nuggets 1 & 4 & 43.09 & 9.18 & 21.30 \\
Chicken nuggets 2 & 3 & 48.54 & 9.45 & 19.47 \\
Popcorn chicken 3 & 9 & 67.80 & 16.19 & 23.88 \\
\hline
\end{tabular}

Chicken nugget 1: 4 pieces were used as one sample. Chicken nugget 2: 3 pieces were used as one sample. Popcorn chicken: 9 pieces were used as one sample. 
Table 4 shows the fatty acid distribution of fat extracted from chicken breast and thigh meats and skins of fried chicken breast and thighs from the three different sources ( 2 fast food restaurants and 1 grocery store). It is interesting to note that palmitic acid was found to be more in the meat samples than in the skins for both breasts and thighs. This ratio was 1.55 to 1.92 times higher in thighs and only 1.18 to 1.4 times higher in the breast meats compared to the skins. Stearic acid was found to be higher in both breast and thigh meats than in the corresponding skins. Oleic acid concentrations were relatively high in both breast and thigh meats and skins. They were in breast meat between $53.43 \%$ to $59.92 \%$ and for skin $49.40 \%$ to $63.29 \%$, for thigh meat $43.89 \%$ to $56.16 \%$ and for skin $46.82 \%$ to $61.90 \%$. Linoleic acid, a precursor for HNE, was quite similar in the breast meats $18.17 \%$ to $20.94 \%$ compared to thigh meats $16.80 \%$ to $23.4 \%$ in the 3 different brands of samples. Linoleic acid concentration was somewhat higher $17.38 \%$ to $31.38 \%$ in breast skin samples and $17.42 \%$ to $31.80 \%$ in all 3 brands of thigh skin samples. In sample 2, skins of both breast and thigh samples had the high levels $31.38 \%$ and $31.80 \%$ of linoleic acid. This may be indicating the type of oil used for frying. Linolenic acids were generally lower in thigh meat than in breast meat 1.31 to 1.98 and 3.38 to 5.39 , respectively. Table 5 shows

Table 4. Fatty acids distribution of fat extracted from Chicken Breasts (CBR) and Chicken Thighs $(\mathrm{CTH})$ meat and skin.

\begin{tabular}{lcccccc}
\hline & & \multicolumn{5}{c}{ Fatty acids (\%) } \\
\cline { 3 - 7 } Sample & Palmitic & Stearic & Oleic & Linoleic & Linolenic \\
\hline Chicken breasts & Meat 1 & 15.35 & 5.37 & 53.43 & 20.44 & 4.46 \\
& Skin 1 & 10.89 & 3.06 & 57.06 & 21.64 & 4.72 \\
& Meat 2 & 12.77 & 4.15 & 56.79 & 20.97 & 3.56 \\
& Skin 2 & 10.75 & 3.99 & 49.40 & 31.38 & 3.38 \\
& Meat 3 & 12.14 & 4.46 & 59.42 & 18.17 & 3.98 \\
& Skin 3 & 8.67 & 3.84 & 63.29 & 17.38 & 5.39 \\
& Meat 1 & 22.53 & 5.71 & 47.17 & 19.11 & $\mathrm{X}$ \\
& Skin 1 & 14.48 & 4.13 & 53.36 & 21.06 & 4.00 \\
& Meat 2 & 19.55 & 6.26 & 43.89 & 23.04 & 1.31 \\
& Skin 2 & 11.37 & 3.98 & 46.82 & 31.80 & 3.51 \\
& Meat 3 & 18.21 & 5.29 & 54.16 & 16.80 & 1.98
\end{tabular}

$\mathrm{X}=$ not detected.

Table 5. Fatty acids distribution of fat extracted from Chicken Nuggets (CNU) and Popcorn Chicken (PCC).

\begin{tabular}{cccccc}
\hline \multirow{2}{*}{ Sample } & \multicolumn{5}{c}{ Fatty acids (\%) } \\
\cline { 2 - 5 } & Palmitic & Stearic & Oleic & Linoleic & Linolenic \\
\hline Chicken nugget 1 & 15.20 & 5.70 & 39.65 & 35.64 & 2.40 \\
Chicken nugget 2 & 11.60 & 5.35 & 49.83 & 30.68 & 1.22 \\
Popcorn chicken 3 & 6.43 & 4.45 & 63.12 & 20.53 & 5.44 \\
\hline
\end{tabular}


the fatty acid distribution of chicken nuggets and popcorn chicken. Chicken nugget samples 1 and 2 had a higher level of palmitic acid concentrations compared to popcorn chicken samples. It was quite similar to the palmitic acid levels in the chicken breasts, between $11.60 \%$ to $15.20 \%$. However, palmitic acid level was only $6.34 \%$ in popcorn chicken. It seems to indicate popcorn chicken samples contain less meat than chicken nuggets and they are very high in coating material. Because of the lower meat content and no skin, it may represent most of the frying oil used, which is absorbed by the coating material during frying. It is interesting to note that all the extracted fats from fried chicken contained relatively high levels of oleic acids ranging from $43.80 \%$ in thigh meat as high as $63.29 \%$ on breast skin. Popcorn chicken extracted fat was also high in oleic acid $63.12 \%$. This also seems to indicate the type of frying oil used. Linoleic and linolenic acid levels for chicken nuggets were similar to the levels of meat and skin levels for fried chicken breast and thighs meats and skins, but popcorn chicken was found to be somewhat higher in linoleic acid level.

\section{3) Thiobarbituric Acid Reactivity (TBARS)}

The formation of secondary lipid peroxidation products such as aldehydes, ketones and related carbonyl compounds were measured by the TBARS assay [42] in the extracted fats of chicken breast and thigh meats, chicken breast and thigh skin samples of the three different commercial brands. TBARS assays were conducted also in the extracted fats of chicken nuggets and popcorn chicken samples. Results are shown in Figure 2(a), Figure 2(b) and Figure 3. Results show that the breast meats were significantly higher than the breast skins in TBARS, expressed by MDA equivalents ( $\mu$ g extracted fat for all 3 samples), but the thigh meats showed only significantly higher level than the thigh skin for sample number 2 and 3, but not sample number 1. The higher level of TBAR values could be that fat extracted from the meats may contain heme irons, which acted as catalysts that accelerated the lipid peroxidation process and resulted in the formation of more aldehydes, ketones and related carbonyl compounds. Some investigation reported myoglobin as a major catalyst of lipid oxidation [45]. It is expected that the fat extracted from chicken thigh meat has a higher TBARS value than the fat extracted from the chicken breast meat because the thigh is a dark meat, which contains more myoglobin than white meat of the chicken breast. Some studies reported that the free ionic iron content plays an important role in the development of lipid oxidation in cooked meat [46]. It was surprising to see that fat extracted from chicken nuggets 1 and 2 were very different from different brands. It is possible that the higher TBARS value related to the amount and type of meat in brand 2 sample compared to brand 1 sample. The popcorn chicken had very low TBAR value possibly relates to the fact that chicken nuggets are containing mostly coating material and very little meat.

4) Formation of HNE in Fried Chicken Breast, Thighs, Chicken Nuggets and Popcorn Chicken from Three Different Fast Food Establishments

Figure 4(a) shows the HNE concentration in the extracted fats of fried 


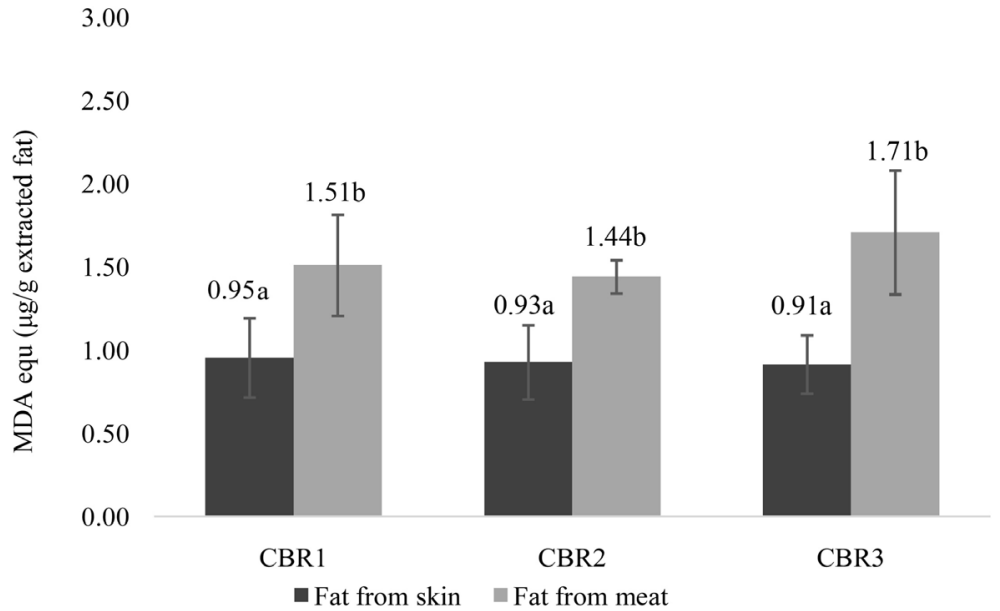

(a)

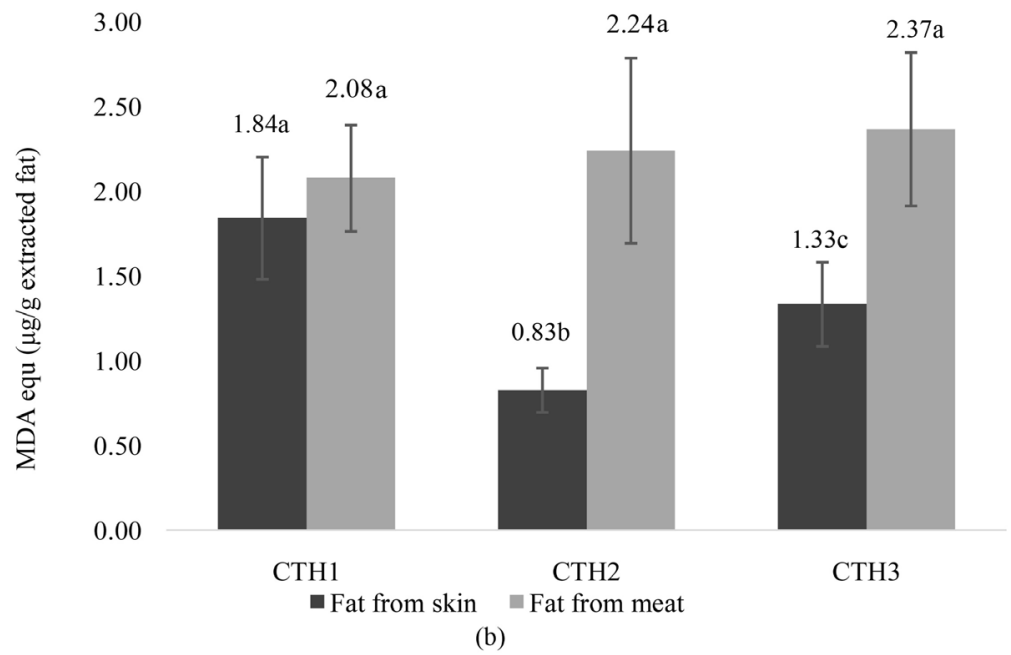

Figure 2. TBARS results of fat extracted from (a) Fried Chicken breast meat and skin samples. (b) Fried chicken thigh meat and skin samples. Groups in each graph with different letters are significantly different, $\mathrm{P}<0.05$.

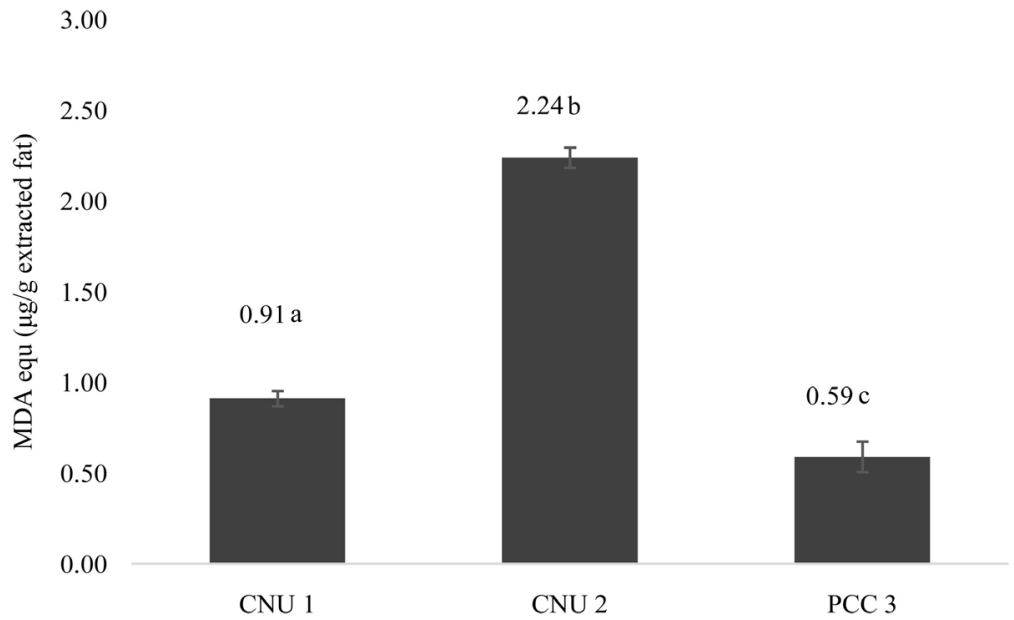

Figure 3. TBARS results of fat extracted from Chicken Nugget (CNU) samples 1 and 2, and Popcorn Chickens (PCC) sample 3. Groups with different letters are significantly different, $\mathrm{P}<0.05$. 


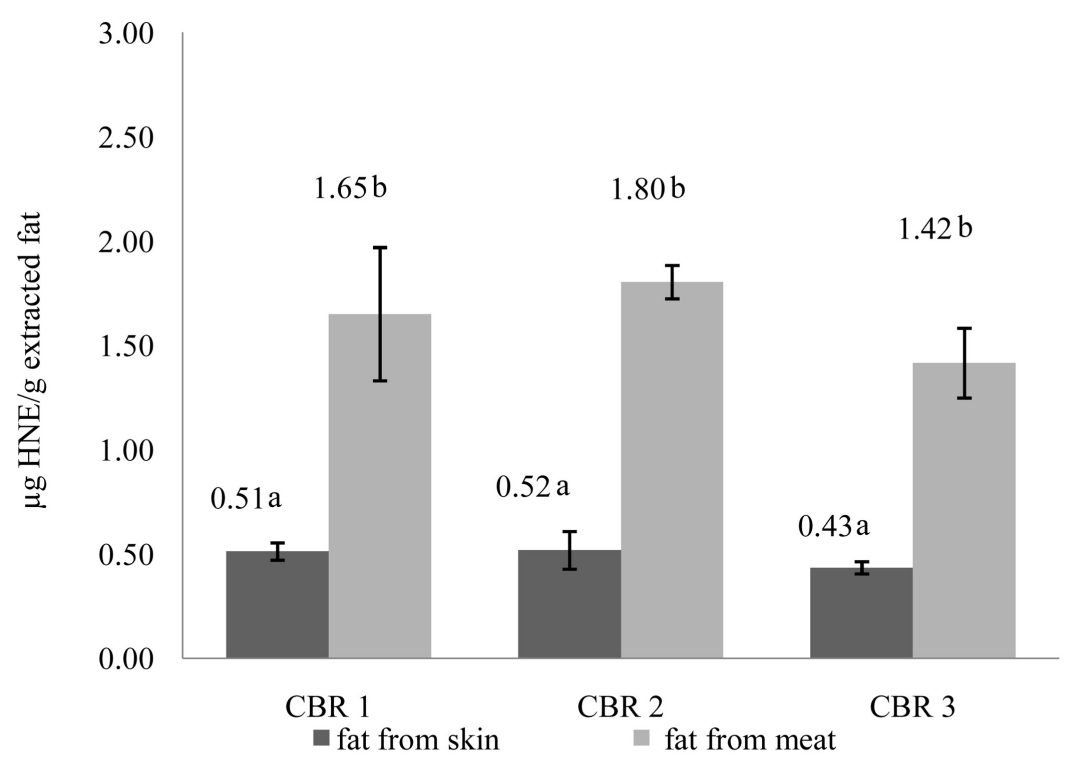

(a)

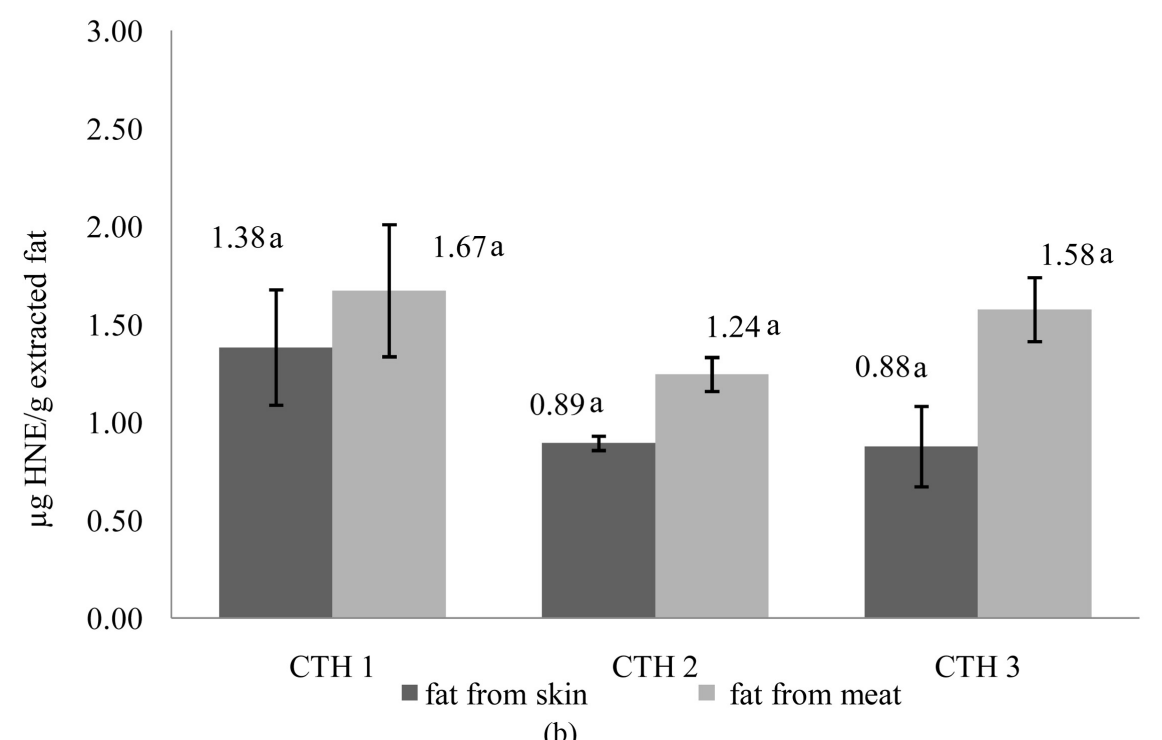

Figure 4. HNE concentrations in fat extracted from (a) Fried chicken breast meat and skin samples. (b) Fried chicken thigh meat and skin samples. Groups in each graph with different letters are significantly different, $\mathrm{P}<0.05$.

chicken breast meats and skins. The HNE concentration was much lower, significantly lower in all 3 brands, in the skin than in the breast meat. The skin was 0.43 to 0.52 and the meat was 1.41 to $1.80 \mu \mathrm{gNE} / \mathrm{g}$ extracted fat, respectively. Figure 4(b) shows the HNE concentration in the thigh meat and skin. While HNE concentration in the fat from breast meat was quite similar to the fat extracted from the thigh meat, the HNE concentration was lower in the breast skin fat than the HNE concentration in the thigh skin fat. The HNE concentrations between thigh meat and skin samples were not significantly different, they were in skin, between 0.88 and 1.38 and in meat between 1.24 and $1.67 \mu \mathrm{g} \mathrm{HNE} / \mathrm{g}$ extracted fat. HNE values are quite low, in breast skins fat, 0.43 to 0.52 , compared 
to thigh skins fat, 0.88 to $1.6, \mu \mathrm{g} \mathrm{HNE} / \mathrm{g}$ extracted fat.HNE concentrations for breast meat fat were between 1.41 and 1.80 and for thigh meat fat were between 1.24 and $1.67 \mu \mathrm{g} H \mathrm{HE} / \mathrm{g}$ extracted fat. These values are quite similar for both breast and thigh meat fats. Figure 5 shows the HNE concentrations in the two different brands of chicken nuggets and popcorn chicken. It is interesting to see that the trend is similar between the TBARS assay (Figure 3) and the HNE concentrations in chicken nuggets brand 1 and 2. The TBARS result is 2.47 times higher and the HNE concentration is 3.28 higher in chicken nuggets brand 2 than in chicken nuggets brand 1 . It is probably due to the linoleic acid concentration of the frying oil used for frying and possibly due to the length of heating time used for the oil for frying because both of these factors could increase the concentration of HNE in the oil. The low level of HNE in popcorn chicken samples seem to indicate, as mentioned previously, that it contains mostly coating material and very little actual meat sample.

The HNE concentration of chicken nuggets sample No. 1 was found to be not significantly different 0.76 from popcorn chicken $0.38 \mu \mathrm{g} \mathrm{HN} / \mathrm{g}$ fat, respectively. However, chicken nugget No. 2 was significantly different $2.46 \mu \mathrm{g} \mathrm{HNE} / \mathrm{g}$ fat from chicken nugget No. 1 . As mentioned before, it seems to indicate the difference maybe due to the frying oil used and the length of heating time of the oil used before frying. HNE formation is related not only to the concentration of linoleic acid but the time and temperature used for the frying oil before frying between the No. 1 and 2 chicken nugget samples.

Table 6 shows the HNE concentrations of the total extracted fat in the fried chicken breasts and thigh meat samples. It ranges for breast meat fat between 4.44 to $7.38 \mu \mathrm{g}$, and for thigh meat fat between 5.58 and $10.52 \mu \mathrm{g} \mathrm{HNE}$.

Table 7 shows the HNE concentrations of the total extracted fat in fried breast chicken skins and thigh skin samples. It ranges for breast skin fat between 4.50 to $6.30 \mu \mathrm{g}$ HNE. The HNE concentration in the thigh skin fat was between 14.19

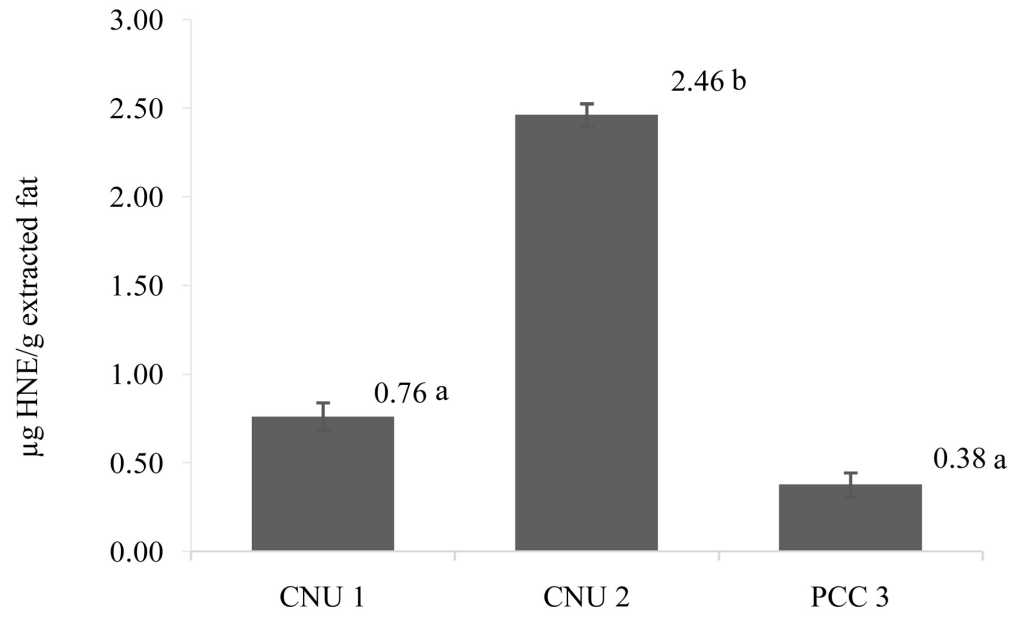

Figure 5. HNE concentrations in fat extracted from Fried Chicken Nugget (CNU) samples 1 and 2, and Popcorn Chickens (PCC) sample 3. Groups with different letters are significantly different, $\mathrm{P}<0.05$. 
Table 6. HNE concentrations of the fat in fried Chicken Breast (CBR) and Thigh (CTH) meat samples.

\begin{tabular}{cccc}
\hline Samples & $\begin{array}{c}\boldsymbol{\mu g} \mathrm{HNE} / \mathrm{g} \\
\text { extracted fat }\end{array}$ & $\begin{array}{c}\text { Total extracted fat of } \\
\text { sample (g) }\end{array}$ & $\begin{array}{c}\text { Total HNE in meat } \\
\text { sample }(\mu \mathrm{g})\end{array}$ \\
\hline CBR-1 & 1.65 & 4.47 & 7.38 \\
CBR-2 & 1.80 & 2.69 & 4.84 \\
CBR-3 & 1.42 & 3.13 & 4.44 \\
CTH-1 & 1.67 & 6.30 & 10.52 \\
CTH-2 & 1.24 & 4.50 & 5.58 \\
CTH-3 & 1.58 & 3.93 & 6.21 \\
\hline
\end{tabular}

Table 7. HNE concentrations of the fat in fried Chicken Breast (CBR) and Thigh (CTH) skin samples.

\begin{tabular}{cccc}
\hline Samples & $\begin{array}{r}\mu \mathrm{g} \mathrm{HNE} / \mathrm{g} \\
\text { extracted fat }\end{array}$ & $\begin{array}{c}\text { Total extracted fat of } \\
\text { sample }(\mathrm{g})\end{array}$ & $\begin{array}{c}\text { Total HNE in skin } \\
\text { fat sample }(\boldsymbol{\mu g})\end{array}$ \\
\hline CBR-1 & 0.51 & 8.82 & 4.50 \\
CBR-2 & 0.51 & 12.35 & 6.30 \\
CBR-3 & 0.43 & 12.90 & 5.55 \\
CTH-1 & 1.38 & 10.04 & 13.86 \\
CTH-2 & 0.89 & 15.94 & 14.19 \\
CTH-3 & 0.88 & 19.25 & 16.94 \\
\hline
\end{tabular}

and $16.94 \mu \mathrm{g} \mathrm{HNE}$, an average 2.75 times higher. It is interesting to note that for some reason the HNE concentrations were higher in the thigh skin fat samples than in the breast skin samples.

Table 8 shows the total HNE concentrations in $100 \mathrm{~g}$ of fried chicken breast and skin samples and thigh and skin samples. These are between 11.25 and 13.88 $\mu \mathrm{g}$ HNE for breast samples and 23.15 to $30.36 \mu \mathrm{g}$ HNE for thigh samples. As an average, the thigh meat and skin samples are 2.15 times higher in $\mu \mathrm{g}$ HNE concentrations in $100 \mathrm{~g}$ fried chicken samples than the breast meat and skin samples. The higher HNE concentrations in the thigh meat samples compared to the breast meat samples, as stated before for the higher TBAR values which are also higher in the thigh meat than the breast meat samples, seem to be related to the dark meat of thigh which contain heme irons, more myoglobin which are acting as catalysts for the higher lipid oxidation process [43] [44].

In conclusion, it was found that lipid peroxidation products such as aldehydes, ketones and related carbonyl compounds measured by the TBARS assay of the extracted fats from fried chicken breasts, thighs, chicken nuggets and popcorn chicken samples resulted in the following. Fried chicken thighs showed as an average 1.44 times higher level of oxidation in the thigh meat than the breast meat. The average TBAR levels were 1.67 times higher in the meat than in the skin for both breast and thigh samples. The toxic 4-hydroxy-2-transnonenal (HNE) was significantly higher in all brands of breast meat than the skin samples. 
Table 8. HNE concentrations in 100 g Chicken Breast (CBR) and Chicken Thigh (CTH) samples.

\begin{tabular}{ccccc}
\hline Samples & $\begin{array}{c}\text { Total Weight of } \\
\text { Skin and Meat } \\
\text { Samples (g) }\end{array}$ & $\begin{array}{c}\text { Mg HNE in } \\
\text { Total Sample } \\
\text { (Skin and } \\
\text { Meat) } \\
\text { Samples (g) }\end{array}$ & $\begin{array}{c}\text { HNE( } \mu \mathrm{g}) \text { in 100 } \\
\text { g Samples (Skin } \\
\text { and Meat) }\end{array}$ & $\begin{array}{c}\text { Average } \mu \mathrm{g} \\
\text { HNE in 100 g } \\
\text { Samples (Skin } \\
\text { and Meat) }\end{array}$ \\
\hline CBR-1 & 85.55 & 11.87 & 13.88 & \\
CBR-2 & 89.00 & 11.14 & 12.52 & 12.55 \\
CBR-3 & 88.80 & 9.99 & 11.25 & \\
CTH-1 & 80.29 & 24.38 & 30.36 & \\
CTH-2 & 85.40 & 19.77 & 23.15 & 26.76 \\
CTH-3 & 86.52 & 23.15 & 26.76 & \\
\hline
\end{tabular}

Two brands of thigh meat were significantly higher than the corresponding thigh skin samples, but one brand was not significantly different between skin and thigh samples because the skin HNE concentration was very high.

The HNE concentration for $100 \mathrm{~g}$ friend chicken breast (skin + meat) as an average for the 3 brands was found to be $12.55 \mu \mathrm{g}$ and for the thigh (skin + meat) $26.75 \mu$ g. The ratio was 2.13 times higher HNE concentration in the thigh compared to the breast samples.

\section{Conflicts of Interest}

The authors declare no conflicts of interest regarding the publication of this paper.

\section{References}

[1] Tappel, A.L. (1977) Protection against Free Radical Lipid Peroxidation Reactions. Advances in Experimental Medicine and Biology, 97, 111-131. https://doi.org/10.1007/978-1-4684-7793-1 7

[2] Chang, S.S., Peterson, R.J. and Ho, C.T. (1978) Chemical Reactions Involved in the Deep-Fat Frying of Foods. Journal of the American Oil Chemists' Society, 55, 718-727. https://doi.org/10.1007/BF02665369

[3] Selke, E., Rohwedder, W.K. and Dutton, H.J. (1980) Volatile Components from Trilinolein Heated in Air. Journal of the American Oil Chemists' Society, 57, 25-30. https://doi.org/10.1007/BF02675520

[4] Frankel, E.N. (1987) Secondary Products of Lipid Oxidation. Chemistry and Physics of Lipids, 44, 73-85. https://doi.org/10.1016/0009-3084(87)90045-4

[5] Grosch, W. (1989) Aromastoffe aus der Lipidperoxidation (Compounds Formed by Peroxidation of Lipids). European journal of Lipid Science and Technology, 91, 1-6.

[6] Frankel, E.N. (1998) Frying Fats. In: Frankel, E.N., Ed., Lipid Oxidation, Oily Press, Dundee, Scotland, 227-248.

[7] Choe, E. and Min, D.B. (2006) Mechanisms and Factors for Edible Oil Oxidation. Comprehensive Reviews in Food Science and Food Safety, 5, 169-185. https://doi.org/10.1111/j.1541-4337.2006.00009.x

[8] German, J.B. (1999) Food Processing and Lipid Oxidation. Advances in Experi- 
mental Medicine and Biology, 459, 23-50.

https://doi.org/10.1007/978-1-4615-4853-9 3

[9] Kanner, J. (2007) Dietary Advanced Lipid Oxidation End Products Are Risk Factors to Human Health. Molecular Nutrition \& Food Research, 51, 1094-1101. https://doi.org/10.1002/mnfr.200600303

[10] Esterbauer, H., Zollner, H. and Schaur, R.J. (1988) Hydroxy Alkenals: Cytotoxic Products of Lipid Peroxidation. ISI Atlas of Science. Biochemistry, 1, 311-317.

[11] Witz, G. (1989) Biological Interactions of $\alpha, \beta$-Unsaturated Aldehydes. Free Radical Biology and Medicine, 7, 333-349. https://doi.org/10.1016/0891-5849(89)90137-8

[12] Esterbauer, H. (1993) Cytotoxicity and Genotoxicity of Lipid Oxidation Products. The American Journal of Clinical Nutrition, 57, 779S-786S. https://doi.org/10.1093/ajcn/57.5.779S

[13] Oarada, M., Miyazawa, T., Fujimoto, K., Ito, E., Terao, K. and Kaneda, T. (1988) Degeneration of Lymphoid Tissues in Mice with the Oral Intake of Low Molecular Weight Compounds Formed during Oil Autoxidation. Agricultural and Biological Chemistry, 52, 2101-2102. https://doi.org/10.1271/bbb1961.52.2101

[14] Julia, K., Maryse, B., Isabelle, J. and Laurent, D. (2015) “Twin Peaks": Searching for 4-Hydroxynonenal Urinary Metabolites after Oral Administration in Rats. Redox Biology, 4, 136-148. https://doi.org/10.1016/j.redox.2014.12.016

[15] Uchida, K. (2003) 4-Hydroxy-2-Nonenal: A Product and Mediator of Oxidative Stress. Progress in Lipid Research, 42, 318-343.

https://doi.org/10.1016/S0163-7827(03)00014-6

[16] Esterbauer, J., Schaur, R.J. and Zollner, H. (1991) Chemistry and Biochemistry of 4-Hydroxynonenal, Malonaldehyde and Related Aldehydes. Free Radical Biology and Medicine, 11, 81-128. https://doi.org/10.1016/0891-5849(91)90192-6

[17] Guchardant, M. and Lagarde, M. (2009) Analysis of Biomarkers from Lipid Peroxidation: A Comprehensive Study. European Journal of Lipid Science and Technolo$g y, 111,75-82$.

[18] Zhong, H. and Yin, H.Y. (2015) Role of Lipid Peroxidation Derived 4-Hydroxynonenal (HNE) in Cancer: Focusing on Mitochrondria. Redox Biology, 4, 193-199.

https://doi.org/10.1016/j.redox.2014.12.011

[19] Comporti, M. (1993) Lipid Peroxidation: Biopathological Significance. Molecular Aspects of Medicine, 1, 199-207. https://doi.org/10.1016/0098-2997(93)90006-Y

[20] Kanazawa, K. and Ashida, H. (1991) Target Enzymes on Hepatic Dysfunction Caused by Dietary Products of Lipid Peroxidation. Archives of Biochemistry and Biophysics, 288, 71-78. https://doi.org/10.1016/0003-9861(91)90166-G

[21] Kaneko, T., Kaji, K. and Matsuo, M. (1988) Cytotoxicities of a Linoleic Acid Hydroperoxide and Its Related Aliphatic Aldehydes toward Cultured Human Umbilical Vein Endothelial Cells. Chemico-Biological Interactions, 67, 295-304. https://doi.org/10.1016/0009-2797(88)90065-8

[22] Schauenstein, E. and Esterbauer, H. (1977) Aldehydes in Biological Systems, Their Natural Occurrence and Biological Activities. Pion Ltd., London, 35-38.

[23] Esterbauer, H., Gebicki, J., Puhl, H. and Jurgens, G. (1992) The Role of Lipid Peroxidation and Antioxidants in Oxidative Modification of LDL. Free Radical Biology and Medicine, 13, 341-390.

[24] Uchida, K., Osawa, T. Hiai, H. and Toylkuni, S. (1995) 4-Hydroxy-2-Nonenal-Trapping ELISA: Direct Evidence for the Release of a Cytotoxic Aldehyde from Oxidized Low Density Lipoproteins. Biochemical and Biophysical Research Communications, 212, 
1068-1073.

https://doi.org/10.1006/bbrc.1995.2078

[25] Palinski, W., Rosenfeld, M.E., Yla-Herttuala, S., Gurtner, G.C., Socher, S.S., Butler, S.W., Parthasarathy, S., Carew, T.E., Steinberg, D. and Witztum, J.L. (1989) Low Density Lipoprotein Undergoes Oxidative Modification in Vivo. Proceedings of the National Academy of Sciences of the United States of America, 86, 1372-1376. https://doi.org/10.1073/pnas.86.4.1372

[26] Hoff, N.F., O’Neil, J., Chisolm III, G.M., Cole, T.B., Quehenberger, O., Esterbauer, H. and Jurgens, G. (1989) Modification of Low Density Lipoprotein with 4-Hydroxynonenal Induces Uptake by Macrophages. Arteriosclerosis, 9, 538-549. https://doi.org/10.1161/01.ATV.9.4.538

[27] Schaur, R.J. (2003) Basic Aspects of the Biochemical Reactivity of 4-Hydroxynonenal. Molecular Aspects of Medicine, 24, 149-159.

https://doi.org/10.1016/S0098-2997(03)00009-8

[28] Leonarduzzi, G., Chiarpotto, E., Biasi, F. and Poli, G. (2005) 4-Hydroxynonenal and Cholesterol Oxidation Products in Atherosclerosis. Molecular Nutrition \& Food Research, 49, 1044-1049. https://doi.org/10.1002/mnfr.200500090

[29] Parola, M., Pinzani, M., Casini, A., Albano, E., Poli, G., Gentilini, A., Gentilini, P. and Dianzani, M.U. (1993) Stimulation of Lipid Peroxidation or 4-Hydroxynonenal Treatment Increases Procollagen Alpha 1 (I) Gene Expression in Human Liver Fat-Storing Cells. Biochemical and Biophysical Research Communications, 194, 1044-1050. https://doi.org/10.1006/bbrc.1993.1927

[30] Tsuneyama, K., Harada, K., Kono, N. Sasaki, M., Saito, T. Gershwin, M.E., Ikemoto, M., Arai, H. and Nakanuma, Y. (2002) Damaged Interlobular Bile Ducts in Primary Biliary Cirrhosis Show Reduced Expression of Glutathione-S-Transferase-pi and Aberrant Expression of 4-Hydroxynonenal. Journal of Hepatology, 37, 176-183. https://doi.org/10.1016/S0168-8278(02)00105-8

[31] Castellani, R.J., Perry, G., Siedlak, S.L., Nunomura, A., Shimohama, S., Zhang, J., Montine, T., Sayre, L.M. and Smith, M.A. (2002) Hydroxynonenal Adducts Indicate a Role for Lipid Peroxidation in Neocortical and Brainstem Lewy Bodies in $\mathrm{Hu}-$ mans. Neuroscience Letters, 319, 25-28. https://doi.org/10.1016/S0304-3940(01)02514-9

[32] Mark, R.J., Lovell, M.A., Markesbery, W.R., Uchida, K. and Mattson, M.P. (1997) A role for 4-Hydroxynonenal, an Aldehydic Product of Lipid Peroxidation, in Disruption of Ion Homeostasis and Neuronal Death Induced by Amyloid Beta-Peptide. Journal of Neurochemistry, 68, 255-264. https://doi.org/10.1046/j.1471-4159.1997.68010255.x

[33] Goicoechea, E., Brandon, E.F.A., Blokland, M.H. and Guillen, M.D. (2001) Fate in Digestion in Vitro of Several Food Components, Including Some Toxic Compounds Coming from Omega-3 and Omega-6 Lipids. Food and Chemical Toxicology, 49, 115-124. https://doi.org/10.1016/j.fct.2010.10.005

[34] Han, I.H. and Csallany, A.S. (2009) Formation of Toxic $\alpha, \beta$-Unsaturated 4-Hydroxyaldehydes in Thermally Oxidized Fatty Acid Methyl Esters. Journal of the American Oil Chemists' Society, 86, 253-260. https://doi.org/10.1007/s11746-008-1343-6

[35] Seppanen, C.M. and Csallany, A.S. (2001) Simultaneous Determination of Lipophilic Aldehydes by High Performance Liquid Chromatography in Vegetable Oil. Journal of the American Oil Chemists' Society, 1253-1260. https://doi.org/10.1007/s11745-001-0422-9 
[36] Seppanen, C.M. and Csallany, A.S. (2002) Formation of 4-Hydroxynonenal, a Toxic Aldehyde in Soybean Oil at Frying Temperature. Journal of the American Oil Chemists' Society, 79, 1033-1038. https://doi.org/10.1007/s11746-002-0598-Z

[37] Seppanen, C.M. and Csallany, A.S. (2006) The Effect of Intermittent and Continuous Heating of Soybean Oil at Frying Temperature on the Formation of HNE and Other $\alpha$, $\beta$-Unsaturated Hydroxyaldehydes. Journal of the American Oil Chemists Society, 83, 121-127. https://doi.org/10.1007/s11746-006-1184-0

[38] Han, I.H. and Csallany, A.S. (2008) Temperature Dependence of HNE Formation in Vegetable Oils and Butter Oil. Journal of the American Oil Chemists' Society, 85, 777-782. https://doi.org/10.1007/s11746-008-1250-x

[39] Yuan, J.Y., Shoeman, D.W. and Csallany, A.S. (2018) Formation of 4-Hydroxy-2Transnonenal, a Toxic Aldehyde in Thermally Treated Olive and Sunflower Oils. Journal of the American Oil Chemists' Society, 95, 813-823. https://doi.org/10.1002/aocs.12098

[40] Seppanen, C.M. and Csallany, A.S. (2004) Incorporation of the Toxic Aldehyde 4-Hydroxy-2-Trans-Nonenal into Food Fried in Thermally Oxidized Soybean Oil. Journal of the American Oil Chemists' Society, 81, 1137-1141. https://doi.org/10.1007/s11746-004-1031-3

[41] Csallany, A.S., Han, I., Shoeman, D.W., Chen, C. and Yuan, J. (2015) 4-Hydroxynonenal (HNE), a toxic aldehyde in French fries from fast food restaurants. Journal of the American Oil Chemists' Society, 92, 1413-1419. https://doi.org/10.1007/s11746-015-2699-Z

[42] Buege, J.A. and August, S.D. (2006) Microsomal Lipid Peroxidation. Microsomal Methods in Enzymology, 52, 300-310.

[43] Schulte, E. (2002) Determination of Higher Carbonyl Compounds in Using Frying Fats by HPLC of DNPH Derivatives. Analytical and Bioanalytical Chemistry, 372, 644-648. https://doi.org/10.1007/s00216-001-1228-0

[44] Metcalfe, L.D. and Schmitz, A.A. (1961) The Rapid Preparation of Fatty Acid Esters for Gas Chromatographic Analysis. Analytical Chemistry, 33, 363-364. https://doi.org/10.1021/ac60171a016

[45] Rhee, K.S., Anderson, L.M. and Sams, A.R. (1996) Lipid Oxidation Potential of Beef, Chicken and Pork. Journal of Food Science, 61, 8-12. https://doi.org/10.1111/j.1365-2621.1996.tb14714.x

[46] Min, B., Nam, K.C., Dordray, J. and Ahn, D.U. (2008) Endogenous Factors Affecting Oxidative Stability of Beef Loin, Pork Loin and Chicken Breast and Thigh Meat. Journal of Food Science, 73, C439-C446. https://doi.org/10.1111/j.1750-3841.2008.00805.x 